\title{
Juan Ansión: trayectoria profesional y aportes a la antropología peruana
}

\section{Patricia Ames}

Pontificia Universidad Católica del Perú pames@pucp.pe

RESUMEN

Este artículo aborda la trayectoria profesional del antropólogo y sociólogo belga-peruano Juan Ansión. Se presentan sus principales intereses de investigación y su desenvolvimiento a lo largo de los años, desde su temprano trabajo en torno al pensamiento mítico en el mundo andino hasta su sostenido compromiso con el tema de la educación en las comunidades rurales, las expectativas y proyectos en torno a la educación y la migración, y el impacto de la violencia política en la escuela. Un tema que interesecta los dos anteriores - la interculturalidad - surge de la necesidad de conceptualizar una nueva propuesta que permita comprender y desafiar las relaciones de subordinación y discriminación entre culturas que experimenta la sociedad peruana. Ansión va a contribuir notablemente en la discusión en torno a la interculturalidad hasta el día de hoy, abarcando no solo la educación, sino también nuevos campos, como el de la justicia y la salud. El artículo aborda su rol como docente universitario, primero en la Universidad Nacional San Cristóbal de Huamanga — con la cual mantuvo una estrecha relación a lo largo de los años-, y posteriormente en la Pontificia Universidad Católica del Perú, donde enseñó a lo largo de más de tres décadas.

Palabras clave: Perú, historia de la antropología, educación, pensamiento mítico, Andes, interculturalidad. 


\section{Juan Ansión: professional career and contribution to Peruvian anthropology}

\section{ABSTRACT}

This paper focuses on the professional trajectory of the belgianperuvian anthropologist and sociologist Juan Ansion. The paper presents his main research interests and their developments over time, from his early work on mythical thought in the Andean world, to his sustained commitment with education in rural communities, the expectations and projects of rural and urban people around education and migration, and the impact of political violence in schools. A topic that intersects those concerns, interculturality, raises from the need to conceptualize a new proposal for understanding and challenging the subordination and discrimination among cultural groups that characterize Peruvian society. Ansión contributed meaningfully in the discussion around interculturality to this day, not limited to education, but including also health and justice. The paper also draws attention to his role as university professor, first in the National University San Cristobal de Huamanga, keeping a long lasting relationship with it, and later the Pontificia Universidad Católica del Peru, where he taught over thirty years.

Keywords: Peru, history of anthropology, education, Andean mithology, Andes, interculturality. 


\section{INTRODUCCIÓN}

Este artículo recoge el discurso realizado en la ceremonia de homenaje a Juan Ansión que celebráramos sus colegas de antropología y ciencias sociales de la Pontificia Universidad Católica del Perú, institución en la que Juan Ansión trabajó a lo largo de más de tres décadas, entre 1984 y 2018, desempeñándose como docente, investigador, coordinador de la especialidad de Antropología y jefe del departamento de Ciencias Sociales. Desde estos diversos roles, Juan Ansión contribuyó al desarrollo de la disciplina antropológica, formando antropólogos y antropólogas, involucrándolos en sus diversos proyectos de investigación y publicando los resultados en artículos y libros de amplia circulación. Todo ello lo convierte en uno de los protagonistas del desarrollo de la antropología en el Perú. Es por ello que ofrecemos esta mirada por su recorrido intelectual en tanto puede aportar en un esfuerzo más amplio por comprender la historia y el desarrollo de la antropología peruana.

\section{I.}

Quiero empezar agradeciendo a mis colegas por la invitación a participar de este homenaje con unas palabras sobre Juan. Es un encargo grato, pero no por ello sencillo, pues hay mucho que decir, y desde múltiples sitios: Juan ha sido mi profesor, mi asesor de tesis, mi colega como docente, y como investigador, ha sido un autor de referencia para mi propio trabajo y sigue siendo un interlocutor con el que siempre es gratificante compartir. Inevitablemente, entonces, este recuento transitará de la mirada externa al testimonio de parte. Para sortear ese recorrido, he optado por ordenarme cronológica y temáticamente.

Juan nació y creció en Bélgica, junto a sus hermanos Jean Pierre y Marie Françoise. En Bélgica, estudió sociología en la Universidad Católica de Lovaina (1968-1972), universidad que mantiene un estrecho vínculo con nuestra facultad $\mathrm{y}$ donde varios profesores de esta casa han recibido su formación de posgrado. 
Su interés por el Perú se inició en esos años de formación y continuó durante su posgrado, ya que su tesis doctoral (defendida en 1984) estuvo dedicada al pensamiento andino y sus reinterpretaciones actuales en la región de Ayacucho (Essais sur la pensée andine et ses réinterprétations actuelles dans la region d'Ayacucho, Pérou).

Pero Juan llegó al Perú mucho antes, una década atrás, a principios de los años 1970, atraído por una poderosa razón: Gloria, su compañera, esposa y madre de sus hijas Nathalie y Mariel. Gloria era egresada de educación en la PUCP y realizaba un posgrado en Lovaina por la misma época. Gracias a Gloria, Juan conoció de la reforma educativa en marcha en el Perú y pudo involucrarse brevemente en el trabajo que se venía haciendo en esos años de transformación del sistema educativo. Pronto, sin embargo, y ante la paralización y posterior desmantelamiento de la reforma, se instaló con su familia en Ayacucho durante varios años, lo que le permitió conocer más de cerca el mundo andino, al que dedicaría muchos de sus trabajos. En Ayacucho también se inició en la docencia universitaria en la Universidad Nacional San Cristóbal de Huamanga, con la que seguirá en contacto a lo largo de varias décadas. El inicio de la violencia armada a principios de la década de 1980, sin embargo, obligó a Juan y su familia a instalarse en Lima. Es entonces, a mediados de la década (1984), cuando Juan empieza su trabajo docente en la PUCP, incorporándose en lo que podríamos llamar un momento de renovación de la plana docente de la especialidad y donde ha cumplido más de treinta años de servicio.

En este apretado recuento de esos años se encuentran, sin embargo, importantes eventos que marcan la obra y los intereses de Juan a lo largo de todo su recorrido académico, así que vuelvo sobre ellos para desarrollarlos un poco más.

II.

Juan, como él mismo contaba hace poco en una sesión del taller de antropología de la educación, es hijo de «Mayo de 1968». Estudiante en esas épocas, fue testigo y partícipe de los vientos de renovación y transformación que recorrieron las aulas universitarias de Europa y América Latina. El retorno renovado de la teoría marxista en aquellos años, por ejemplo, se puede encontrar entre las herramientas teóricas que utiliza en su tesis doctoral, de la mano con la sociología del conocimiento de Mannheim y los aportes de Durkheim. Juan estudia en esta tesis el pensamiento mítico en el mundo andino, situándolo en el marco de la situación de dominación colonial y el choque cultural con el fin de comprender las ambigüedades del sincretismo producido en estas circunstancias. 
En este primer trabajo, que se convierte en su primer libro - Desde el rincón de los muertos: el pensamiento mítico en Ayacucho (1987) — se aprecian intereses que seguiría desarrollando a lo largo de su vida académica, como las desiguales relaciones de poder y dominación que se heredan del hecho colonial, sus impactos en el mundo y la cultura andina, los diferentes lenguajes y modos de pensamiento que conviven en el espacio andino y las dificultades para su mutua comprensión, un tema que lo llevaría más adelante a la problemática de la interculturalidad.

Otro tema que lo encamina en esta dirección se plasma en su segundo libro, publicado a fines de la década de 1980: La escuela en la comunidad campesina (1989), donde aborda la educación como objeto de análisis antropológico y comienza una línea de trabajo que continúa hasta la actualidad. En correspondencia con su interés por el pensamiento mítico, Juan presta atención a los diferentes relatos que se recogen en el mundo andino en torno a la escuela, al lugar ambiguo que esta ocupa, evidenciando la desconfianza y el rechazo ante algunos mitos, pero también el deseo por - y la apropiación de-la escolaridad en otros, lo cual, junto a las narrativas que recoge en una investigación que abarca varias regiones, le permite plantear cambios importantes en la relación entre los pobladores andinos y la idea de la escolarización, y la importancia que esta adquiere para ellos.

Una década después explorará también la educación en el imaginario de los pobladores urbanos como miembro de un equipo interdisciplinario, cuyo resultado es el libro Educación: la mejor herencia (1998) y constata el lugar central que esta ocupa en las aspiraciones de diversos grupos sociales. En medio, una larga vinculación con escuelas y maestros, tanto urbanos como rurales, unida a la publicación de varios artículos, lo convierten en uno de los pocos antropólogos en esa época sistemáticamente dedicado al estudio y la reflexión sobre la temática educativa. Por ello, en 2008 será elegido el primer presidente de la recién fundada Sociedad de Investigación Educativa Peruana (SIEP).

Pero volvamos un poco en el tiempo: a fines de los 1980 edita también el libro Pishtacos: de verdugos a sacaojos (1989), donde retoma el pensamiento mítico en torno al pishtaco, pero en el contexto de terror y violencia que vive la sociedad peruana y que, con el desplazamiento a raíz del conflicto armado, hace su aparición en el contexto urbano.

La violencia y el conflicto armado serán otros temas que indaga con interés, desde la mirada de la antropología política y desde su propia experiencia como testigo de su desarrollo en Ayacucho y la UNSCH, tratando de comprender a sus principales actores y, particularmente, la forma en que construyen y proyectan sus discursos en textos e imágenes, así como sus estrategias de captación. 
Sobre esto último, y en vinculación con la escuela, a principios de la década de 1990 conduce una investigación con otros colegas que se publica en el libro La escuela en tiempos de guerra: una mirada a la educación desde la crisis y la violencia (1992), donde revela la precaria situación de maestros y alumnos en el contexto del conflicto armado interno, los usos de la escuela por SL y el MRTA, las estrategias de captación y amenaza que se emplearon en el espacio educativo y los desafíos para que la educación peruana no continúe abonando en comportamientos autoritarios, sino que pueda colaborar en construir espacios y comportamientos democráticos, una de las recomendaciones que dos décadas después enfatizaría la Comisión de la Verdad y Reconciliación tras investigar los hechos de la violencia.

Pero no voy a hacer aquí un recuento de todos los trabajos de Juan, porque excedería el tiempo permitido (una búsqueda en el catálogo PUCP arroja ocho páginas de resultados entre libros y artículos).

Me he detenido en estos primeros trabajos porque en ellos se aprecian los intereses que va desarrollando y que van confluyendo también en su preocupación por la interculturalidad, el último tema que quisiera resaltar [aunque tendré que dejar fuera todo su interesante trabajo sobre los migrantes peruanos en el exterior, sus redes y sus familias, ver por ejemplo Redes y maletas: capital social en familias de migrantes (2013), Más allá de las remesas: familias de migrantes en América Latina (2009), Los que se quedan: familias de emigrados de un distrito de Lima (2008)].

Desde su interés por la educación y la cultura andina, Juan identifica tempranamente la necesidad de definir y trabajar el concepto de interculturalidad, sobre el cual plantea algunas de las primeras conceptualizaciones de las que disponemos en el país, con su libro conjunto con Madeleine Zúñiga: Interculturalidad y educación en el Perú (1997). En este libro se plantea el necesario reconocimiento de la interculturalidad de hecho que se vive en el Perú, atravesada por desiguales relaciones de poder, y la necesidad de plantear un proyecto diferente, una interculturalidad como principio normativo que permita «construir — sobre la base del reconocimiento del derecho a la diversidad y en franco combate contra todas las formas de discriminación y desigualdad social — relaciones dialógicas y equitativas entre los miembros de universos culturales diferentes». En ese sentido, el libro plantea que la interculturalidad es fundamental para la construcción de una sociedad democrática y para cualquier proyecto educativo de cara al siglo XXI.

En los veinte años que han pasado desde la publicación de ese libro, Juan ha seguido refinando el concepto, discutiéndolo, investigando las prácticas y las 
ideas sobre la interculturalidad, indagando por su aplicación en el campo educativo, primero en la escuela, posteriormente en la universidad [ver por ejemplo Ciudadanía intercultural: conceptos y pedagogías desde América Latina (2008); Educar en ciudadanía intercultural: experiencias y retos en la formación de estudiantes universitarios indígenas (2007)], y luego en otros campos, como la justicia y el derecho: su más reciente publicación está dedicada justamente a ello y lleva por título Justicia intercultural y bienestar emocional (2017).

III.

He querido esbozar rápidamente los temas que Juan ha desarrollado y que deben resultar familiares para sus lectores antes de pasar a su trabajo como docente, porque en este se han reflejado también todas sus preocupaciones académicas. Conociendo su interés por el desarrollo de la teoría que se aprecia desde sus primeros libros y artículos, no es extraño que Juan haya estado a cargo desde muy temprano de los cursos de teoría y que sea muy recordado por ello entre sus estudiantes. Una de ellas, que no puede estar aquí hoy, le comentaba, por ejemplo, lo siguiente:

Tus exámenes de teoría antropológica y de antropología política siempre me fascinaron porque justamente nos obligaban a pensar la teoría desde otro ángulo, a dejar de lado el paporreteo impregnado en nuestras venas después de doce años de educación básica. Hubo un examen en el que teníamos que poner a discutir a Marx y Durkheim; ambos muertos se encontraban en el universo y discutían (igenial!) (VR).

Otra egresada rememora su curso de Antropología Política, otro de sus temas de interés:

Recuerdo mucho las clases de Antropología Política, donde [Juan] sabía ser incisivo para lograr que como grupo llegáramos a captar los alcances del texto que discutíamos. Al decir que es respetuoso o paciente, no quiere decir que no fuera riguroso $(\mathrm{LG})$.

Como estos breves testimonios permiten ver, en sus cursos Juan trasmitía la importancia y la necesidad de una sólida base teórica, explicaba con entusiasmo las propuestas teóricas de diversos autores y nos invitaba a usarlos, a dialogar con ellos, a perderle el miedo a la teoría y verla como lo que es: una herramienta para la construcción de conocimiento, para la interpretación de la realidad. 
Como asesor, Juan también es muy recordado por su capacidad de escucha, su habilidad para orientar y su capacidad para apoyarnos en el camino de culminar una tesis.

Lo que más recuerdo es su don de buen oidor [...] Juan sabía (sabe) escuchar, $\mathrm{y}$ es en ese tiempo abierto que recuerdo haber elaborado o aclarado algunos de los puntos más importantes de la tesis. Más que decirme «tienes que ir por aquí» $\mathrm{o}$ «te falta $\mathrm{x}, \mathrm{y}, \mathrm{z}$ » (¡que faltaban!), él empleaba una aproximación mayéutica $[\ldots]$ con suaves preguntas, o simplemente pidiendo que elaborara oralmente algún punto, me ayudó a ver por dónde tenía que ir (LG).

Luego, como asesor, fue siempre cálido. Era agradable, había mucho respeto por su trabajo y su opinión, pero siempre fueron reuniones amables donde se podía preguntar, dudar; recuerdo que conversábamos horas. Y él decía algo así como: «Todo está bien... sigue». Siempre apoyó, empujó a seguir, y será por eso que todas sus asesoradas terminamos y sustentamos la tesis de licencia [...] No sé si ahora los profesores tenemos tanto tiempo [...] De verdad que me acuerdo largas horas en su oficina donde él escuchaba siempre paciente mis dudas y angustias de tesista novata (FU).

Quizás uno de los secretos de su éxito como asesor era que compartía su propia fórmula personal: hay que investigar lo que te apasiona. A él lo apasionaban (aún lo apasionan) la política, la educación, la cultura andina. Y estaba dispuesto a perseguir a estos apasionantes objetos de conocimiento sea que fueran o no temas clásicos o de moda. Estaba dispuesto a dejarnos ir en nuevas direcciones, explorar temas, plantear preguntas no solo a los «otros» sino también a ese «nosotros diverso» del que participábamos, como sociedad diversa y pluricultural que apenas se reconocía como tal.

Juan fue activo también en crear espacios extracurriculares para encontrarse, debatir y discutir esos temas apasionantes: formó el taller de cultura política, y más adelante el de antropología de la escuela y promovió publicaciones que recogieran trabajos de sus participantes [como el libro Autoridad en espacios locales: una mirada desde la antropología (2000)]. También involucró a sus estudiantes en sus propios proyectos de investigación, permitiéndonos entrenarnos en la observación, la aplicación de entrevistas, los diversos métodos y técnicas que luego tendríamos que diseñar y aplicar por nuestra cuenta.

Mantuvo y mantiene lazos con su alma mater, Lovaina, y con frecuencia invitaba a colegas y profesores visitantes a dar charlas y seminarios en la facultad cuando investigaban en el Perú, y mantenía lazos y redes con colegas de otras latitudes (actualmente es vicepresidente de la sección de Ciencias Sociales de la 
Federación Internacional de Universidades Católicas). También invitaba a sus estudiantes a leer más allá del Perú, a nutrirse de otras fuentes, a no quedarse encerrados en la «particularidad» peruana. Y se encargaba de que los libros llegaran: aprovechaba sus viajes a conferencias para traer libros a la biblioteca que de otra manera difícilmente llegaban al Perú. Para él la formación entonces, no empezaba ni terminaba en la clase: era una tarea mucho más amplia.

Pero las clases eran también importantes, como ya hemos visto en los testimonios que he compartido. Desde mi recuerdo, algo sin duda característico de Juan era que traía la realidad a sus clases también, y no la realidad remota, idílica o congelada de un bucólico mundo andino (de un «buen» o «mal» salvaje, como también fue recurrente en aquel tiempo). Más bien se trataba de la realidad que golpeaba la puerta, la que en aquellos años que nos tocaron compartir hacía temblar los cristales con los coches bombas, que arrebataba la vida de tantos jóvenes y también la de nuestros propios compañeros ${ }^{1}$.

En sus clases de antropología política podíamos encontrarnos un día con los afiches y panfletos de Sendero Luminoso y analizar con él sus componentes, su lenguaje, su iconografía, entender cómo persuadía, cómo trasmitía una imagen de fuerza, de ciencia, de verdad, comprenderlo como un actor político, pero también cultural, con sus propios mitos. O podíamos discutir los muchos cambios, aspiraciones y esperanzas depositadas en la escuela a los que los pobladores andinos o aquellos instalados en los márgenes de la ciudad se aferraban como parte de un proyecto de transformación de sus propias vidas y las de sus hijos.

Con estos ejemplos Juan nos alejaba de una visión exotizante del otro y nos recordaba que la antropología podía ayudarnos a comprender esa realidad compartida de diversidad y desigualdad en la que todos, investigadores e investigados, habitábamos. Y también nos mostraba que esa comprensión podía ayudarnos a transformarla. Después de todo, ya lo he dicho, Juan era un hijo del mayo de 1968 y nunca ha abandonado la convicción de que una sociedad más justa, más democrática, más humana y más intercultural es posible. Como profesor, fuimos afortunados de contar con su gran capacidad pedagógica para trasmitir estas ideas. Como investigador, nos beneficiamos con su gran capacidad intelectual y compromiso personal para demostrarlas y contribuir a construirlas.

Por todo eso, hoy queremos decirte: muchas gracias Juan.

En 1990 fue detenido y desaparecido el estudiante de sociología Ernesto Castillo Páez. En 1992, en el atentado de la calle Tarata perdió la vida César Cortez, estudiante de antropología, y su hermana Cecilia Cortez, estudiante de economía. 